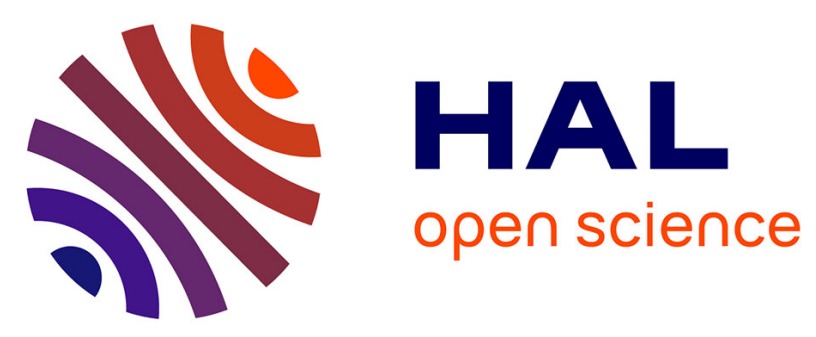

\title{
Key Role of Intramolecular Metal Chelation and Hydrogen Bonding in the Cobalt-Mediated Radical Polymerization of $\mathrm{N}$-Vinyl Amides
}

Antoine Debuigne, Aurélie Morin, Anthony Kermagoret, Yasmine Piette, Christophe Detrembleur, Christine Jérôme, Rinaldo Poli

\section{To cite this version:}

Antoine Debuigne, Aurélie Morin, Anthony Kermagoret, Yasmine Piette, Christophe Detrembleur, et al.. Key Role of Intramolecular Metal Chelation and Hydrogen Bonding in the Cobalt-Mediated Radical Polymerization of N - Vinyl Amides. Chemistry - A European Journal, 2012, 18 (40), pp.1283412844. 10.1002/chem.201201456 . hal-02909737

\section{HAL Id: hal-02909737 https://hal.science/hal-02909737}

Submitted on 29 Jul 2021

HAL is a multi-disciplinary open access archive for the deposit and dissemination of scientific research documents, whether they are published or not. The documents may come from teaching and research institutions in France or abroad, or from public or private research centers.
L'archive ouverte pluridisciplinaire HAL, est destinée au dépôt et à la diffusion de documents scientifiques de niveau recherche, publiés ou non, émanant des établissements d'enseignement et de recherche français ou étrangers, des laboratoires publics ou privés. 


\title{
Key Role of Intramolecular Metal Chelation and Hydrogen Bonding in the Cobalt- Mediated Radical Polymerization of $N$-Vinyl amides.
}

\author{
Antoine Debuigne, ${ }^{*[a]}$ Aurélie N. Morin, ${ }^{[b, c]}$ Anthony Kermagoret, ${ }^{[a]}$ Yasmine Piette, ${ }^{[a]}$ Christophe \\ Detrembleur, ${ }^{[\mathrm{a}]}$ Christine Jérôme ${ }^{[\mathrm{a}]}$ and Rinaldo Poli*[b-d].
}

\begin{abstract}
This work reveals the preponderance of an intramolecular metal chelation phenomenon in a controlled radical polymerization system involving the reversible trapping of the radical chains by a cobalt complex, i.e. the bis(acetylacetonato)cobalt(II). The cobalt-mediated radical polymerization (CMRP) of a series of $N$-vinyl amides was considered in order to evidence the effect of the cobalt chelation by the amide moiety of the last monomer unit of the chain. The latter reinforces the cobalt-polymer bond in the order $\mathrm{N}$ -
\end{abstract}

vinylpyrrolidone $<N$-vinyl caprolactam $<N$-methyl- $N$-vinyl acetamide, and is responsible for the optimal control of the polymerizations observed for the last two monomers. Such a double linkage between the controlling agent and the polymer, via a covalent bond and a dative one, is unique in the field of controlled radical polymerization and represents a powerful opportunity to fine tune the equilibrium between latent and free radicals. The possible hydrogen bond formation is also taken into account in the case of $N$-vinyl acetamide and $N$-vinyl formamide.
These results are essential for understanding factors influencing a $\mathrm{Co}$ $\mathrm{C}$ bond strength in general, and the CMRP mechanism in particular, but also for developing a powerful platform for the synthesis of new precision poly( $N$-vinyl amide)s, an important class of polymers which sustains numerous applications today.

Keywords: Vinyl amide $\bullet$ cobalt
chelation $\bullet$ hydrogen bonding $\bullet$
DFT calculations $\bullet$ controlled
radical polymerization

\section{Introduction}

Organometallic compounds have deeply marked the field of polymer synthesis by coordination polymerization, with the metal activity being intimately related to the nature of the coordination sphere. ${ }^{[1-4]}$ Controlled radical polymerization (CRP), that prevents irreversible radical termination reactions and allows the precision design of polymers, is no exception. ${ }^{[5,6]}$ A wide range of metallic compounds are used as catalysts for the reversible activation of the

[a] Center for Education and Research on Macromolecules (CERM)

Chemistry Department

University of Liège (ULg)

Sart-Tilman, B6a, 4000 Liège, Belgium.

Fax: (+32) 4-366 3497

E-mail: adebuigne@ulg.ac.be

[b] Laboratoire de Chimie de Coordination (LCC), CNRS,

205 Route de Narbonne, BP 44099

F-31077 Toulouse Cedex 4, France.

Fax: +33(0)561553003

E-mail: Rinaldo.Poli@1cc-toulouse.fr

[c] Université de Toulouse, UPS, INPT,

F-31077 Toulouse Cedex 4, France.

[d] Institut Universitaire de France,

103, bd Saint-Michel,

75005 Paris, France. "dormant" polymer species into the active growing radical chains in the so-called atom transfer radical polymerization (ATRP). This polymerization strategy relies on the reversible exchange of a halogen atom between the radical chains and a metal center, and the activity of the ATRP catalyst strongly depends on the metal ligands. ${ }^{[5-9]}$

Other organometallic compounds act as CRP controlling agents by reversibly trapping the radicals with the formation of a metalpolymer bond. This technique, called organometallic-mediated radical polymerization (OMRP), ${ }^{[10-15]}$ is particularly well developed with cobalt complexes (CMRP) ${ }^{[13-20]}$ and is very efficient for controlling the polymerization of reactive unconjugated monomers such as vinyl esters, ${ }^{[14,16,21]} N$-vinyl pyrrolidone $(N \mathrm{VP})^{[22-25]}$ or vinyl imidazolium. ${ }^{[26]}$ Again, the choice of the metal ligands is crucial; moreover, the cobalt-carbon strength can be adjusted by the addition of Lewis base additives able to coordinate the metal center such as pyridine, water, dimethylformamide (DMF) or dimethylsulfoxide (DMSO). ${ }^{[27-29]}$ The major activating effect of the coordinating agents consists in the stabilization of the released cobalt(II) with formation of bis-adducts. ${ }^{[27-29]}$ It is therefore possible to use such additives in order to change the activation/deactivation equilibrium and operate an efficient switch in the build-up of block copolymers. ${ }^{[30]}$ Importantly, in the absence of external coordinating agents, an intramolecular cobalt chelation phenomenon involving coordinating groups on the polymer chains becomes possible, as verified for the polymerization of vinyl acetate (VAc) mediated by bis(acetylacetonato)cobalt(II), Co(acac) ${ }_{2}{ }^{[21]}$ Such a double linkage between the controlling agent and the polymer chains, via a covalent 
bond and a dative one, has so far been evidenced only for this $\mathrm{Co}(\mathrm{acac})_{2}$-mediated polymerization in the whole field of CRP. It is a unique powerful lever for fine tuning the equilibrium between "dormant" and active species involved in the controlled polymerization. A DFT study of the above mentioned VAc polymerization in the presence of $\mathrm{Co}(\mathrm{acac})_{2}$ suggested that the ester moiety of the last VAc unit of the dormant species chelates the cobalt(III) at the end of the chain and forms a five-member ring, which provides an extra-stabilization of about $3 \mathrm{Kcal}^{\mathrm{mol}}{ }^{-1}$ to the cobalt-polymer bond. ${ }^{[21]}$ However, very few experimental data support this assumption at the moment. Although amides are known to be stronger Lewis bases than esters through their electron-richer carbonyl group, the possible effect of an intramolecular chelation of the cobalt center on the course of the $N \mathrm{VP}^{[22-25]}$ and $N \mathrm{VCL}^{[31]}$ polymerization has never been considered. Whatever the conditions used, the CMRP of these monomers have always been presented as a simple reversible capping of the radical chains by the metal following the equilibrium between species $\mathbf{1}$ and $\mathbf{2}$ (Scheme 1).

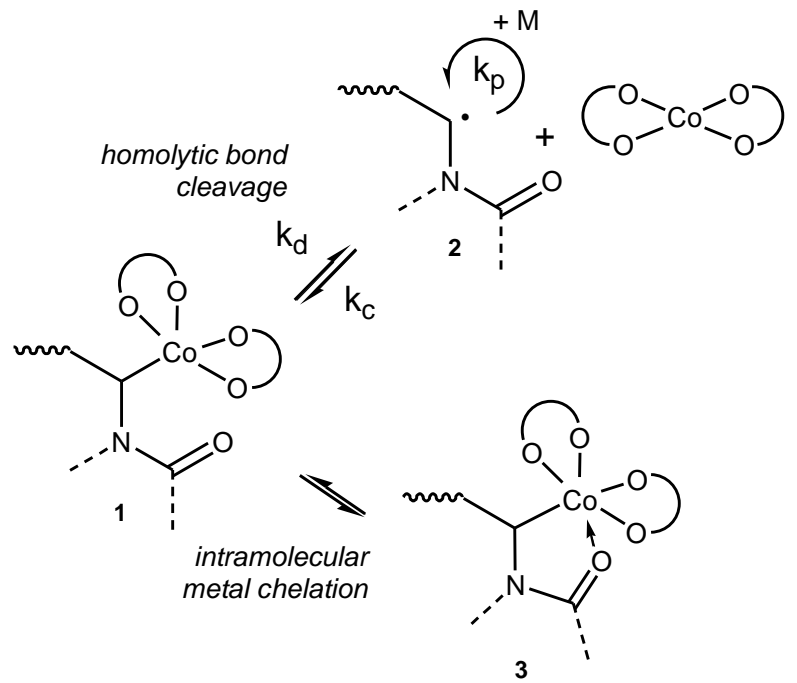

Scheme 1. Metal chelation in the cobalt-mediated radical polymerization of viny amides.

In this contribution, we explore the CMRP of a series of $N$-vinyl amides (see Chart 1) in order to evidence the preponderance of the chelated species 3 (Scheme 1) in the CMRP mechanism based on kinetics data and theoretical calculations. $N$-vinyl amides are easily polymerized via a radical mechanism and differ from acrylamides in that the amide function is linked to the double bond via the nitrogen atom. As a consequence, the growing radical is quite reactive due to the lack of stabilizing group, rendering the controlled radical polymerization difficult, as illustrated by limited number of reports on the CRP of this family of monomers. ${ }^{[32-42]}$ Therefore, experimental conditions were adapted in order to take advantage of this intramolecular metal coordination and improve the control of the polymerizations of the vinyl amides. This work constitutes an important step towards a powerful platform for the synthesis of new well-defined poly( $N$-vinyl amide)s in order to fulfil the increasing demand for this important class of materials which combines valued properties such as water solubility, thermoresponsiveness, ${ }^{[43-45]}$ biocompatibility. ${ }^{[46,47]}$ The latter already sustains numerous applications including controlled release systems $^{[43,48-50]}$ and hydrates formation inhibition in gas and oil production lines. ${ }^{[51,52]}$<smiles>C=CNC=O</smiles>

NF<smiles>C=CN1CCCC1=O</smiles>

NP<smiles>C=CNC(C)=O</smiles>

NA<smiles>C=CN1CCCCCC1=O</smiles>

MVL<smiles>C=CN(C)C(C)=O</smiles>

MMVA<smiles>C=COC(C)=O</smiles>

VAc
Chart 1. Structures of the unconjugated monomers considered in this study.

\section{Results and Discussion}

\section{(a) Polymerizations}

The polymerization of several $N$-vinyl amides was carried out in the presence of $\mathrm{Co}(\mathrm{acac})_{2}$, which is the simplest and most versatile complex used in CMRP until now. ${ }^{[13]}$ The evolution of the molecular parameters $\left(\mathrm{M}_{\mathrm{n}}\right.$ and $\left.\mathrm{M}_{\mathrm{w}} / \mathrm{M}_{\mathrm{n}}\right)$ of the resulting polymers and the monomer consumption were monitored in order to appreciate the level of control and the kinetics of the polymerization. In this study, we used a preformed alkyl-cobalt derivative, which consists in an oligopoly(vinyl acetate) with an average number of four VAc units end-capped by the cobalt complex ([Co(acac) $)_{2}$ $\left.\left.\left(\mathrm{CH}(\mathrm{OAc}) \mathrm{CH}_{2}\right)_{4}-\mathrm{R}\right]\right),{ }^{[21,28]}$ as initiator. The thermal treatment of this alkyl-cobalt derivative promotes the homolytic cleavage of the Co-C bond and the release of both the initiating radical and the controlling agent in the polymerization medium. Although both degenerative chain transfer and reversible termination contributions are reported for CMRP, the former requires an influx of radicals along the polymerization which is not the case when using an alkyl-cobalt derivative (R-Co(acac)2). The development of this initiating system not only drastically improved the CMRP of VAc but was also decisive to ensure the control of other important monomers like acrylonitrile $(\mathrm{AN})^{[53]}$ and $n$-butyl acrylate $(n \mathrm{BuA}){ }^{[54]}$ In the present study, the CMRP of $N$-vinyl amides was thus conducted with the same R-Co(acac $)_{2}$ initiator and compared to the polymerization of VAc (See Table 1).

Table 1. Cobalt-Mediated Radical Polymerization of $N$-alkyl-vinyl amides in bulk.

\begin{tabular}{|c|c|c|c|c|c|c|}
\hline Entry & Monomer & $\mathbf{T}\left[{ }^{\circ} \mathbf{C}\right]$ & Time & $\begin{array}{c}\text { Conv } \\
{[\%]}\end{array}$ & $\begin{array}{c}\mathbf{M}_{\mathbf{n}} \\
{[\mathrm{g} / \mathrm{mol}]}\end{array}$ & $\mathbf{M}_{\mathrm{w}} / \mathbf{M}_{\mathbf{n}}$ \\
\hline \multirow{3}{*}{1} & \multirow{3}{*}{ VAc } & \multirow{3}{*}{40} & $4 \mathrm{~h}$ & 16 & $5000^{[a]}$ & 1.05 \\
\hline & & & $8 \mathrm{~h}$ & 28 & $9300^{[a]}$ & 1.09 \\
\hline & & & $16 \mathrm{~h}$ & 60 & $19300^{[a]}$ & 1.18 \\
\hline \multirow{2}{*}{2} & \multirow{2}{*}{$N \mathrm{VP}$} & \multirow{2}{*}{40} & $2.5 \mathrm{~min}$ & 8 & $12700^{[b]}$ & 1.12 \\
\hline & & & $3.5 \mathrm{~min}$ & 33 & $25000^{[\mathrm{b}]}$ & 1.30 \\
\hline \multirow{3}{*}{3} & \multirow{3}{*}{$N \mathrm{VCl}$} & \multirow{3}{*}{40} & $1 \mathrm{~h}$ & 21 & $10200^{[\mathrm{b}]}$ & 1.04 \\
\hline & & & $2 \mathrm{~h}$ & 31 & $17800^{[b]}$ & 1.03 \\
\hline & & & $3 \mathrm{~h}$ & 40 & $24200^{[\mathrm{b}]}$ & 1.02 \\
\hline \multirow{3}{*}{4} & \multirow{3}{*}{$N \mathrm{MVA}$} & \multirow{3}{*}{40} & $2 \mathrm{~h}$ & 14 & $4800^{[\mathrm{b}]}$ & 1.07 \\
\hline & & & $7 \mathrm{~h}$ & 32 & $12700^{[b]}$ & 1.08 \\
\hline & & & $14 \mathrm{~h}$ & 62 & $24700^{[b]}$ & 1.14 \\
\hline \multirow{3}{*}{5} & \multirow{3}{*}{$N \mathrm{MVA}$} & \multirow{3}{*}{60} & $20 \mathrm{~min}$ & 19 & $9300^{[\mathrm{b}]}$ & 1.05 \\
\hline & & & $40 \mathrm{~min}$ & 31 & $13800^{[b]}$ & 1.12 \\
\hline & & & $60 \mathrm{~min}$ & 48 & $24800^{[b]}$ & 1.30 \\
\hline
\end{tabular}

$[$ Monomer $] /\left[\mathrm{RCo}(\mathrm{acac})_{2}\right]=380$, bulk polymerization. [a] Measured by SEC in THF using a PS calibration. [b] Measured by SEC in DMF using a MALLS detector. 
As previously described, ${ }^{[28]} 40^{\circ} \mathrm{C}$ is an ideal temperature for the CMRP of VAc in bulk (Table 1, entry 1). The molar mass distribution of the PVAc is very narrow $\left(M_{w} / M_{n} \sim 1.1\right)$ and the $M_{n}$ is predictable based on the monomer/initiator molar ratio and the monomer conversion. Above this temperature, termination becomes more important whereas the polymerization is rather slow below $40^{\circ} \mathrm{C}$. The absence of solvent, likely to coordinate the cobalt complex, allows the intra-molecular cobalt chelation phenomenon described in the introduction that strengthens the Co-C bond. For this reason the polymerization of $N$-vinyl amides was first conducted at $40^{\circ} \mathrm{C}$ in bulk to possibly beneficiate of this extrastabilization.

Although the CMRP of NVP has already been investigated with some success, ${ }^{[22-25]}$ the polymerization was carried out either in the presence of a co-monomer or in solution (anisole or methanol) at low temperature (below $30^{\circ} \mathrm{C}$ ). Here, a solution of the R-Co(acac) initiator in $N \mathrm{VP}$ was heated at $40^{\circ} \mathrm{C}$ (Table 1, entry 2). The polymerization was very fast but not deprived of any control as illustrated by the increase of the $\mathrm{M}_{\mathrm{n}}$ with the conversion and the moderate molar-mass dispersity ( 1.3). Considering the results obtained for VAc under the same conditions (Table 1, entry 1), the deactivation of the PNVP growing chains by $\mathrm{Co}(\mathrm{acac})_{2}$ is clearly not as efficient compared to PVAc. The overlay of the kinetic curves presented in figure 1 clearly emphasizes the drastic difference in the polymerization rates of VAc and NVP. The expected stabilization of the PNVP-Co(acac)2 dormant species by intra-molecular coordination of the metal by the amide function at the chain-end (Scheme 1, species 3) does not seem to contribute as effectively as in the VAc case to the stabilization of the dormant species. As will be shown in the DFT section, the rapid polymerization of $N \mathrm{VP}$ can mostly be attributed to the strong stabilization of the released $\mathrm{Co}(\mathrm{acac})_{2}$ by monomer coordination.

The CMRP of NVCL, another cyclic vinyl amide with a sevenmember lactam ring, was then considered. A recent report deals with the radical polymerization of this monomer using the same R$\mathrm{Co}(\mathrm{acac})_{2}$ initiator at $30^{\circ} \mathrm{C}$ in DMF. ${ }^{[31]}$ Although well-defined PNVCL were produced under those conditions $\left(\mathrm{M}_{\mathrm{w}} / \mathrm{M}_{\mathrm{n}} \sim 1.2\right)$, a better polymerization control might result in bulk. Indeed, DMF is a coordinating solvent and can compete with the likely intramolecular metal chelation by the terminal amide which is susceptible to stabilize the dormant cobalt(III) species and limit the instantaneous concentration of free radical in the medium. ${ }^{[28]}$ Since NVCL is characterized by a melting point around $37^{\circ} \mathrm{C}$, its bulk polymerization at $40^{\circ} \mathrm{C}$ was carried out by first melting $N \mathrm{VCL}$ at $40^{\circ} \mathrm{C}$ under an inert atmosphere, followed by the addition onto the R-Co(acac) 2 initiator (Table 1, entry 3). The kinetics of the CMRP of $N \mathrm{VCL}$ was intermediate between those of VAc and NVP (See Figure 1), i.e. $40 \%$ monomer conversion in $3 \mathrm{~h}$. From the control point of view, the bulk process is much better for NVCL than the previously described solution procedure in DMF. First, the dependence of the molar mass versus the monomer conversion is linear and $\mathrm{M}_{\mathrm{w}} / \mathrm{M}_{\mathrm{n}}$ remained below 1.1. The regular shift of the very narrow peaks on the overlay of the size exclusion chromatograms (SEC) is another proof of the outstanding control of NVCL polymerization under these conditions (Figure S1a). In this case, the ratio between theoretical and experimental molar masses was evaluated as 0.87. Expectedly, PNVCL samples with twice higher molar masses were collected when the $[N \mathrm{VCL}] /\left[\mathrm{R}-\mathrm{Co}(\mathrm{acac})_{2}\right]$ molar ratio was doubled (see Figure 2). The low molar mass dispersities observed for the PNVCL having a molar mass as high as 65000 g.mol ${ }^{-1}$ suggest that CMRP is a technique of choice for the controlled polymerization of this monomer. Finally, it is striking that the slight structural differences between $N \mathrm{VCL}$ and $N \mathrm{VP}$, two vinyl lactams, lead to such contrasting kinetics and quality of control. These observations are rationalized in the DFT section.

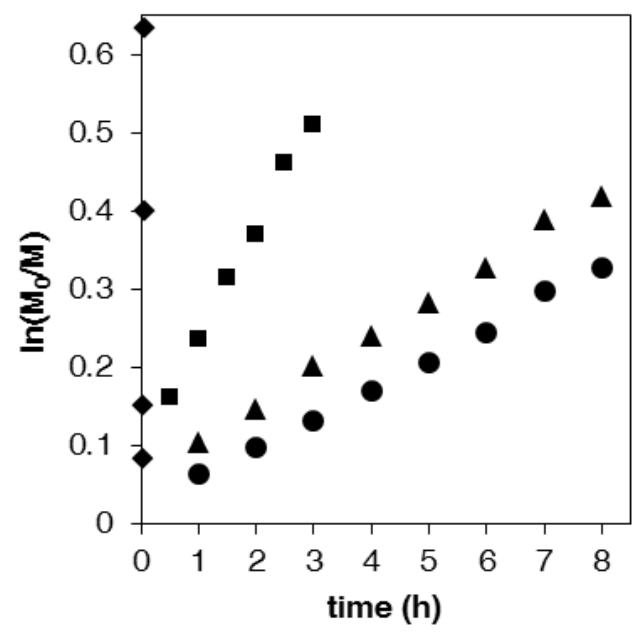

Figure 1. Time dependence of $\ln \left[\mathrm{M}_{0}\right] /[\mathrm{M}]$ (M:monomer) for the CMRP of VAc $(\bullet)$ NVP ( $), N V C L(\bullet)$ and NMVA $(\boldsymbol{\Delta})$ initiated in bulk at $40^{\circ} \mathrm{C}$ by a low molecular weight alkyl cobalt adduct. [monomer] $/\left[\mathrm{Co}(\mathrm{acac})_{2}-\left(\mathrm{CH}(\mathrm{OAc}) \mathrm{CH}_{2}\right)_{44}-\mathrm{R}_{0}\right]=380$.

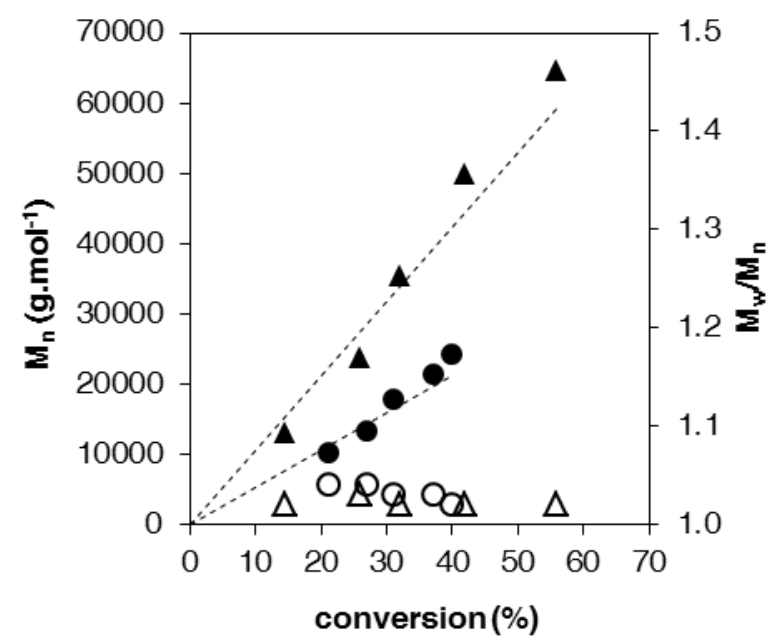

Figure 2. Dependence of the absolute molar mass (full symbols) and the molar mass distribution (hollow symbols) on the monomer conversion for the CMRP of NVCL initiated in bulk at $40^{\circ} \mathrm{C}$. $(\bullet)[N V C L] /\left[\mathrm{Co}(\mathrm{acac})_{2}-\left(\mathrm{CH}(\mathrm{OAc}) \mathrm{CH}_{2}\right)_{<4}-\mathrm{R}_{0}\right]=380$. ( $(\boldsymbol{\Delta})$ $[N \mathrm{VCL}] /\left[\mathrm{Co}(\mathrm{acac})_{2}-\left(\mathrm{CH}(\mathrm{OAc}) \mathrm{CH}_{2}\right)_{<4}-\mathrm{R}_{0}\right]=760$. The dotted lines represent the theoretical dependence of the molar mass vs conversion.

The CMRP of a non-cyclic $N$-alkyl-vinyl amide was also considered in this study, i.e. the $N$-methyl- $N$-vinyl acetamide (NMVA). In spite of the very interesting properties of the parent polymer (PNMVA), no report deals with the controlled polymerization of this monomer until now. For the sake of comparison, the polymerization was conducted under the same experimental conditions (bulk at $40^{\circ} \mathrm{C}$, table 1 entry 4 ). In this case, the polymerization rate was very similar to that of VAc (Figure 1) and the polymerization control was excellent: the molar mass is strictly dictated by the monomer conversion and the $[N \mathrm{MVA}] /[\mathrm{R}-$ $\mathrm{Co}(\mathrm{acac})_{2}$ ] molar ratio and the molar-mass dispersity is low (between 1.1 and 1.2, Figure 3). The control of the NMVA polymerization is confirmed by the clear shift of the SEC peaks with 
time towards higher molecular weight (Figure S1b in the Supporting Information).

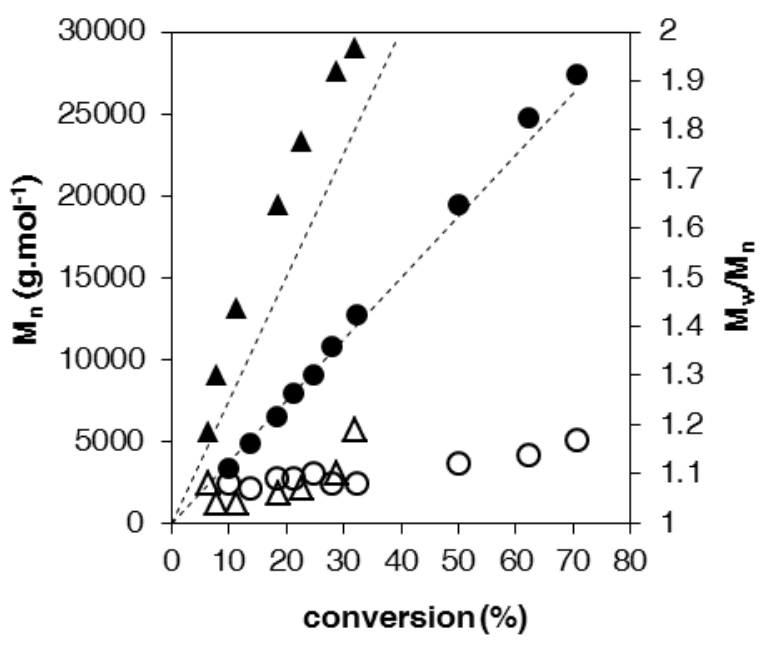

Figure 3. Dependence of the absolute molar mass (full symbols) and the molar mass distribution (hollow symbols) on the monomer conversion for the CMRP of NMVA initiated in bulk at $40^{\circ} \mathrm{C}$. $[N \mathrm{MVA}] /\left[\mathrm{Co}(\mathrm{acac})_{2}-\left(\mathrm{CH}(\mathrm{OAc}) \mathrm{CH}_{2}\right)_{<4}-\mathrm{R}_{0}\right]=380(\bullet)$ and 760

$(\boldsymbol{\Lambda})$. The dotted lines represent the theoretical dependence of Mn vs conversion.

Then, we studied the CMRP of $N$-vinyl formamide $(N \mathrm{VF})$ and $N$-vinyl acetamide (NVA), two monomers bearing a hydrogen on the nitrogen atom of the amide group. After mixing the $N \mathrm{VF}$ with the R$\mathrm{Co}(\mathrm{acac})_{2}$ initiator at room temperature, a highly exothermic reaction occurred and the mixture became extremely viscous within two minutes. The monomer conversion reached $67 \%$ and the molecular parameters of the PNVF were determined by aqueous SEC $\left(M_{n}\right.$ cal PEO $=20200$ g. $\left.\mathrm{mol}^{-1}, M_{w} / M_{n}=1.4\right)$. Indeed, no control can be claimed for $N \mathrm{VF}$ under these conditions. The bulk polymerization of $N \mathrm{VA}$ could not be carried out at $40^{\circ} \mathrm{C}$ because the melting point of this crystalline monomer is $55^{\circ} \mathrm{C}$. The CMRP of $N$ VA was thus realized at $60^{\circ} \mathrm{C}$ in the melted monomer phase and the monomer consumption was almost complete within a few seconds after addition of the melted NVA onto the $\mathrm{R}-\mathrm{Co}(\mathrm{acac})_{2}$ initiator $\left(M_{n}\right.$ MALLS $\left.=62400 \mathrm{~g} \cdot \mathrm{mol}^{-1}, \mathrm{M}_{\mathrm{w}} / \mathrm{M}_{\mathrm{n}}=2.34\right)$. For the sake of comparison, the polymerization of NMVA was also performed at $60^{\circ} \mathrm{C}$ (Table 1, entry 5) and, as expected, the polymerization was much faster compared to $40^{\circ} \mathrm{C}$ but the cobalt complex still exerts some control on the polymerization as illustrated by the regular shift of the SEC chromatograms with the polymerization time (Figure S2) Therefore, it is clear that the substitution of the methyl group of $N$ MVA by a hydrogen atom is sufficient to alter the control of the polymerization.

Finally, we examined the effect of the addition of NVA on the course of the CMRP of NMVA. This copolymerization initiated at $40^{\circ} \mathrm{C}$ in bulk $([N \mathrm{MVA}] /[N \mathrm{VA}]=1)$ by $\left[\mathrm{Co}(\mathrm{acac})_{2}-\left(\mathrm{CH}(\mathrm{OAc}) \mathrm{CH}_{2}\right)_{44-}\right.$ $\mathrm{R}]$ was quite fast compared to the homopolymerization of $N \mathrm{MVA}$ (see kinetics Figure S3 in the Supporting Information) but controlled, as assessed by the shift of narrow SEC peaks towards higher molar masses with time (Figure 4). The composition of a PNVA-coPNMVA copolymer prepared under the same conditions was evaluated by ${ }^{1} \mathrm{H}$ NMR in $\mathrm{D}_{2} \mathrm{O}(N \mathrm{VA} / N \mathrm{MVA}$ molar ratio in the copolymer $=55 / 45$, see Figure S4). In this copolymerization, the trapping of the radical chains having NMVA as last unit by $\mathrm{Co}(\mathrm{acac})_{2}$ is efficient enough to produce well-defined statistical copolymers containing NVA units. The effect of both the intramolecular cobalt chelation and the ability of $N \mathrm{VA}$ to form $\mathrm{N}$ $\mathrm{H} \cdots \mathrm{O}=\mathrm{C}$ hydrogen bonds on the course of the (co)polymerization is discussed in the modeling section (vide infra).

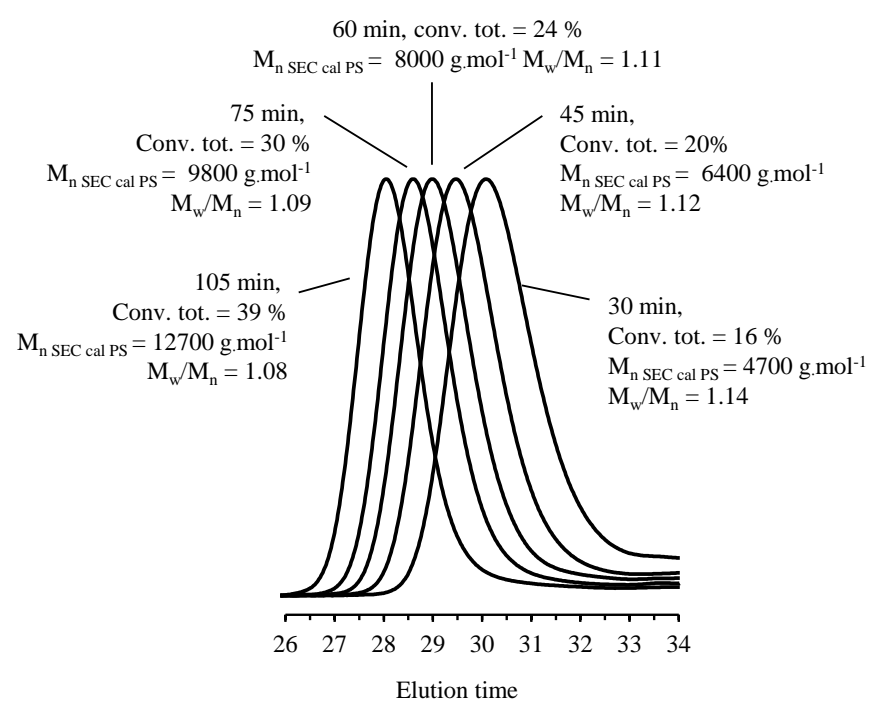

Figure 4. Time evolution of the size exclusion chromatograms for the statistical CMRP of $N \mathrm{MVA} / N \mathrm{NA}(50 / 50)$ initiated in bulk at $40^{\circ} \mathrm{C}$ by a low molecular weight alkyl cobalt adduct. $[N \mathrm{MVA}] /[N \mathrm{VA}] /\left[\mathrm{Co}(\mathrm{acac})_{2}-\left(\mathrm{CH}(\mathrm{OAc}) \mathrm{CH}_{2}\right)_{<4}-\mathrm{R}_{0}\right]=95 / 95 / 1$.

To summarize the experimental polymerization investigation, the vinyl amide monomers shown in Chart 1 give rise to a wide range of polymerization rates under similar conditions in spite of their relatively similar electronic structure, featuring the same $\mathrm{CH}_{2}=\mathrm{CH}-\mathrm{N}\left(\mathrm{R}_{1}\right)-\mathrm{CO}-\mathrm{R}_{2}$ framework. The polymerization becomes faster in the order $N \mathrm{MVA}<N \mathrm{VCL}<N \mathrm{VP}<N \mathrm{VA}, N \mathrm{VF}$.

\section{(b) Kinetic scheme}

The expression of the rate of polymerization in a controlled radical polymerization process operating by a reversible termination mechanism is given by the rate of propagation, $R_{\mathrm{p}}=k_{\mathrm{p}}\left[\mathrm{P}_{\mathrm{n}}{ }^{\circ}\right][\mathrm{M}]$, with the radical concentration expressed in terms of the activation/deactivation pre-equilibrium. For the OMRP process examined here, the kinetic scheme and the corresponding rate equation are given in Scheme 2, where $\left[\mathrm{Co}^{\mathrm{III}}\right]$ represents the total concentration of $\mathrm{Co}^{\mathrm{III}}$ complexes $\left(\left[\mathrm{Co}(\mathrm{acac})_{2}\left(\mathrm{P}_{\mathrm{n}}\right)\right]+\right.$ $\left.\left[\mathrm{Co}(\mathrm{acac})_{2}\left(\mathrm{P}_{\mathrm{n}}\right)(\mathrm{L})\right]\right)$ and $\left[\mathrm{Co}^{\mathrm{II}}\right]$ represents the total concentration of $\mathrm{Co}^{\mathrm{II}}$ complexes $\left(\left[\mathrm{Co}(\mathrm{acac})_{2}\right]+\left[\mathrm{Co}(\mathrm{acac})_{2}(\mathrm{~L})\right]+\left[\mathrm{Co}(\mathrm{acac})_{2}(\mathrm{~L})_{2}\right]\right)$. The derivation of this equation is detailed in the Supporting Information.

$$
\begin{aligned}
& K_{\mathrm{OMRP}}=k_{\mathrm{a}} / k_{\mathrm{d}}
\end{aligned}
$$

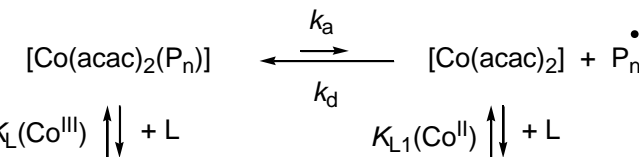

$$
\begin{aligned}
& {\left[\mathrm{Co}(\mathrm{acac})_{2}\left(\mathrm{P}_{\mathrm{n}}\right)(\mathrm{L})\right] \quad\left[\mathrm{Co}(\mathrm{acac})_{2}(\mathrm{~L})\right]} \\
& K_{\mathrm{L} 2}\left(\mathrm{Co}^{\prime \prime}\right) \uparrow \downarrow+\mathrm{L} \\
& {\left[\mathrm{Co}(\operatorname{acac})_{2}(\mathrm{~L})_{2}\right]} \\
& \dot{\mathrm{P}_{\mathrm{n}}}+\mathrm{M} \stackrel{k_{\mathrm{p}}}{\longrightarrow} \underset{\mathrm{P}_{\mathrm{n}+1}}{\dot{*}}
\end{aligned}
$$$$
R_{\mathrm{p}}=k_{\mathrm{p}} K_{\mathrm{OMRP}} \frac{\left[\mathrm{Co}^{\prime \prime \prime}\right]}{\left[\mathrm{Co}^{\prime \prime}\right]} \frac{\left\{1+\mathrm{K}_{\mathrm{L} 1}\left(\mathrm{Co}^{\prime \prime}\right)[\mathrm{L}]+\mathrm{K}_{\mathrm{L} 1}\left(\mathrm{Co}^{\prime \prime}\right) \mathrm{K}_{\mathrm{L} 2}\left(\mathrm{Co}^{\prime \prime}\right)[\mathrm{L}]^{2}\right\}}{\left\{1+\mathrm{K}_{\mathrm{L}}\left(\mathrm{Co}^{\prime \prime \prime}\right)[\mathrm{L}]\right\}}[\mathrm{M}]
$$

Scheme 2. Kinetic scheme and rate equation for an OMRP process. 
Thus, one of the most important parameters is the rate constant of the propagation step, which is dependent of the nature of the monomer. This, however, can be modulated by the $\mathrm{Co}{ }^{\mathrm{III}} / \mathrm{Co}^{\mathrm{II}}$ ratio, by the formation constants of the ligand adducts to both $\mathrm{Co}^{\mathrm{II}}$ and $\mathrm{Co}^{\mathrm{III}}$, and by the ligand concentration. Addition of $\mathrm{Co}(\mathrm{acac})_{2}$ to the polymerization medium slows down the reaction, as already demonstrated in previous work. ${ }^{[54]}$ Coordination of added external Lewis base, on the other hand, accelerates the polymerization process. ${ }^{[27]}$ This is the reason for the faster polymerization of VAc in the presence of pyridine relative to $\mathrm{NEt}_{3},{ }^{[27]}$ or in the presence of DMSO relative to DMF. ${ }^{[28]}$ The effect of ligand coordination on the polymerization of VAc has been successfully assessed, at least at a semi-quantitative level, by DFT calculations. The energetic diagram for $\mathrm{L}=\mathrm{DMF}$ is shown as an example in Figure 5. It will also serve as a reference for the vinyl amide polymerization systems discussed below.

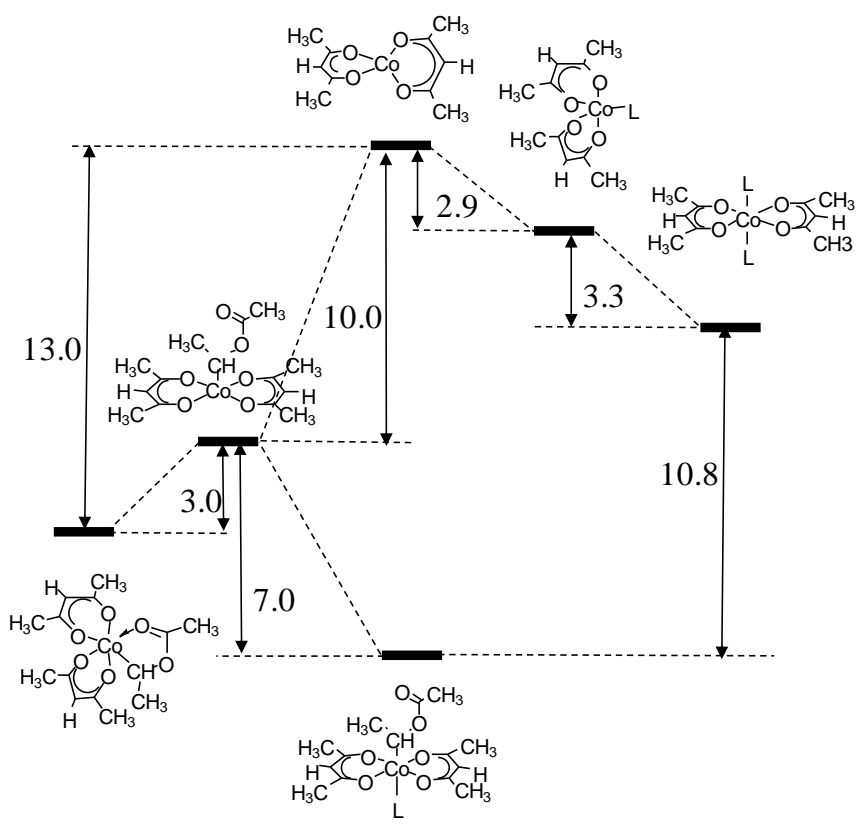

Figure 5. Energy diagram of the OMRP equilibrium in the $\mathrm{Co}(\mathrm{acac})_{2}$-mediated polymerization of VAc in the presence of DMF. Values are $\Delta \mathrm{H}$ in $\mathrm{kcal} / \mathrm{mol}$ at the BPW91* level (see Computational Details). Data are taken from ref. ${ }^{[28]}$

This diagram shows that chelation provides $3.0 \mathrm{kcal} / \mathrm{mol}$ of stabilization to the alkylcobalt(III) system, where the alkyl chain is modeled by replacing the polymer chain, beyond the cobalt-bonded monomer unit, by an $\mathrm{H}$ atom. Homolytic dissociation, yielding [Co(acac $\left.)_{2}\right]$ and the model $\mathrm{CH}_{3} \mathrm{COOCH}\left(\mathrm{CH}_{3}\right)^{\circ}$ radical, costs another $10.0 \mathrm{kcal} / \mathrm{mol}$, so that in the absence of Lewis bases, activation of the dormant species requires an estimated enthalpic cost of 13.0 $\mathrm{kcal} / \mathrm{mol}$. However, DMF coordination provides enthalpic stabilization to the $\mathrm{Co}^{\mathrm{III}}$ system by $7.0 \mathrm{kcal} / \mathrm{mol}$ and to the $\mathrm{Co}^{\mathrm{II}}$ system by 2.9 and $3.3 \mathrm{kcal} / \mathrm{mol}$ for the first and second coordination. The overall energetic balance of the activation equilibrium is that the $13.0 \mathrm{kcal} / \mathrm{mol}$ in the absence of Lewis base are now reduced to $10.8 \mathrm{kcal} / \mathrm{mol}$ between the dormant species, $\left[\mathrm{Co}(\mathrm{acac})_{2}\left(\mathrm{CH}(\mathrm{Me}) \mathrm{OOCCH}_{3}\right)(\mathrm{DMF})\right]$, and the deactivator, $\left[\mathrm{Co}(\mathrm{acac})_{2}(\mathrm{DMF})_{2}\right]$. It is worth noting that the latter is a labile complex (ligand dissociation and exchange is very fast for high-spin $\mathrm{Co}^{\mathrm{II}}$ complexes) and therefore this is a legitimate rapid trap for the radical chain via the 5 -coordinate $\left[\mathrm{Co}(\mathrm{acac})_{2}(\mathrm{DMF})\right]$.

This diagram does not have absolute quantitative value because, in addition to the computational errors and approximations (e.g. neglect of solvation effects), equilibrium is expressed by the $\Delta \mathrm{G}$ function, which cannot be accurately evaluated in a condensed phase. Therefore, as already done in the previously published analyses, ${ }^{[21,24,28,29,53,55]}$ we shall limit our attention to the estimation of $\Delta \mathrm{H}$, obtained from the DFT calculations by applying zero-point vibrational energy (ZPVE), PV and thermal correction in the gas phase under standard conditions.

Unfortunately, the propagation rate constants are not available for all 5 monomers of interest in this work, thus a finer analysis of the relative polymerization rates under $\mathrm{Co}(\mathrm{acac})_{2}$-mediated OMRP conditions cannot be carried out. To the best of our knowledge, only the $k_{\mathrm{p}}$ value for $N \mathrm{VP}\left(953 \mathrm{~L} \mathrm{~mol}^{-1} \mathrm{~s}^{-1} \text { at } 20^{\circ} \mathrm{C}\right)^{[56,57]}$ and $N \mathrm{VF}(670 \mathrm{~L}$ $\mathrm{mol}^{-1} \mathrm{~s}^{-1}$ at $\left.25^{\circ} \mathrm{C}\right),{ }^{[58]}$ both values corresponding to bulk conditions, are reported in the literature. These two values are rather close to each other, while the two monomers are representative of secondary and primary amides, cyclic and acyclic, respectively. Given the similarity of the electronic structure of the radicals and monomers, we could consider, to a first approximation, that the propagation coefficients of the other missing monomers should not be too different from these two values. In the subsequent computational study, we shall focus on the modulation of the rate by differences in the OMRP equilibrium position.

\section{(c) DFT calculations.}

When considering the structural differences of the five investigated monomers, we note that NVP, NVCL and NVMA have a fully alkyl substituted $\mathrm{N}$ atom, whereas $N \mathrm{VA}$ and $N \mathrm{VF}$ carry a $\mathrm{H}$ atom on the $\mathrm{N}$ atom, which has a different electronic effect and is a possible source of hydrogen bonding with the carbonyl functions. The first three monomers should have very similar electronic properties, but whereas NVP and NVCL are cyclic, NMVA is acyclic and ring tension may play a role in the generation of the dormant species. In order to study the impact of these structural differences on the rate of polymerization, we embarked in a DFT investigation of all these systems, in comparison with the previously published study of the VAc system. ${ }^{[28]}$

Taking the above described picture of the VAc system (Figure 5) as a guide, the first question is the relative strength of the $\mathrm{Co}^{\mathrm{III}}$ chain bond and any extra stabilization provided by chelation. Like for the VAc system, the polymer chain was modeled by an $\mathrm{H}$ atom beyond the Co-bonded monomer unit, as shown in Scheme 3.
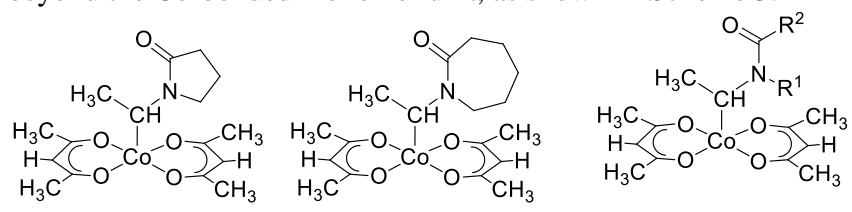

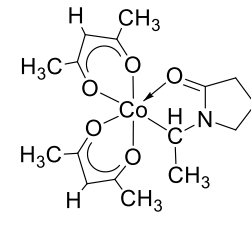

NVP

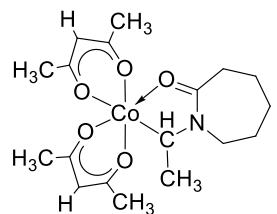

NVCL

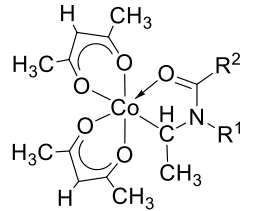

$\mathrm{R}^{1}, \mathrm{R}^{2}=\mathrm{Me}, \mathrm{Me} ;$ NVMA $\mathrm{R}^{1}, \mathrm{R}^{2}=\mathrm{H}, \mathrm{Me}: N V A$ $\mathrm{R}^{1}, \mathrm{R}^{2}=\mathrm{H}, \mathrm{H}: \quad N V F$
Scheme 3. Models of the 5- and 6-coordinate $\mathrm{Co}^{\mathrm{III}}$ dormant species for the polymerization of the vinyl amide monomers.

The calculations, carried out at the same level of theory as those previously reported for the VAc system (see details in the 
Experimental Section) on the three processes illustrated in Scheme 4 afford the results summarized in Table 2. For comparison, the Co$\mathrm{CH}_{3}$ bond dissociation enthalpy in $\mathrm{Co}(\mathrm{acac})_{2}\left(\mathrm{CH}_{3}\right)$ has also been calculated. A graphical representation with views of the optimized structures is available in the Supporting Information (Figure S5).

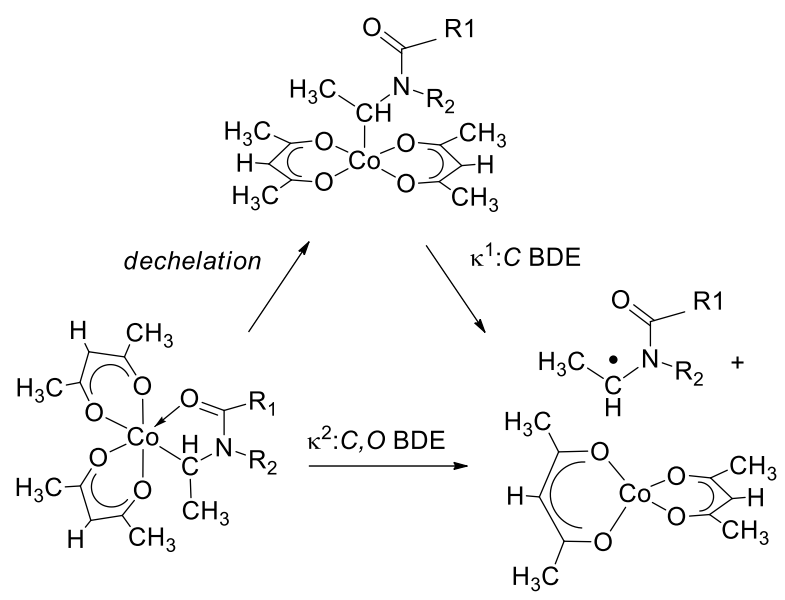

Scheme 4. Dechelation and homolytic bond cleavage processes for the dormant species in $\mathrm{Co}(\mathrm{acac})_{2}$-mediated polymerization of vinyl amide monomers.

Table 2. Calculated enthalpy changes (in $\mathrm{kcal} / \mathrm{mol}$ ) for the processes shown in Scheme 4.

\begin{tabular}{lccc}
\hline Complex & dechel. & $\mathbf{\kappa}^{\mathbf{1}}: \boldsymbol{C}$ BDE & $\begin{array}{c}\boldsymbol{\kappa}^{2}: \boldsymbol{C}, \boldsymbol{O} \\
\mathbf{B D E}\end{array}$ \\
\hline $\mathrm{Co}(\mathrm{acac})_{2}(N \mathrm{VPH})$ & 4.3 & 7.3 & 11.6 \\
$\mathrm{Co}(\mathrm{acac})_{2}(N \mathrm{VCLH})$ & 5.2 & 9.5 & 14.7 \\
$\mathrm{Co}(\mathrm{acac})_{2}(N \mathrm{VMAH})$ & 7.8 & 8.7 & 16.5 \\
$\mathrm{Co}(\mathrm{acac})_{2}(N \mathrm{VAH})$ & 4.7 & 9.4 & 14.1 \\
$\mathrm{Co}(\mathrm{acac})_{2}(N \mathrm{VFH})$ & 3.0 & 10.0 & 13.0 \\
$\mathrm{Co}(\mathrm{acac})_{2}(\mathrm{VAcH})$ & 3.0 & 10.0 & 13.0 \\
$\mathrm{Co}(\mathrm{acac})_{2}(\mathrm{CH})$ & & 20.1 & \\
\hline
\end{tabular}

A first observation is that the intrinsic $\mathrm{Co}-\mathrm{C}$ bond strength in the dormant chain models (enthalpy of Co-C bond formation to yield the $\kappa^{1}: C$ product, in the $7.3-10.0 \mathrm{kcal} / \mathrm{mol}$ range) is only slightly smaller than in the $\mathrm{Co}(\mathrm{acac})_{2}(\mathrm{VAcH})$ model (see Figure 5 and Table 2) and much smaller than in $\mathrm{Co}(\mathrm{acac})_{2}\left(\mathrm{CH}_{3}\right)$. The radicals containing an $\mathrm{N}-\mathrm{H}$ bond (from the $N \mathrm{VA}$ and $N \mathrm{VF}$ monomers) yield slightly stronger bonds, comparable in strength with that of the radical from VAc, possibly resulting from released steric pressure. The same argument may also rationalize the weaker bond with the $N$ VPH radical, because the 5-membered pyrrolidone ring is less flexible than the 7-membered caprolactone ring, while it takes more space than two Me groups in NVMAH and is constrained by the Co$\mathrm{CH}-\mathrm{N}$ angle requirement to remain in close proximity of the acetylacetonate ligands (see view in Figure S5).

The chelation resulting from coordination of the carbonyl group provides the greatest stabilization for the secondary amide systems (in the order $N \mathrm{VMA}>N \mathrm{VCL}>N \mathrm{VP}$ ) and less for the primary amides $(N \mathrm{VA}>N \mathrm{VF})$. This can be attributed to the inductive effect of the second alkyl substituent, rendering the carbonyl oxygen atom a better electron donor. The greater chelating ability of $N \mathrm{VA}$ relative to $N \mathrm{VF}$ can also be attributed to an inductive effect (Me group bonded to the $\mathrm{CO}$ donor function). The reason for the relative order of chelation strength for the dialkyl substituted amides may be attributed to the ring tension, which is non-existent for NVMA, intermediate for $N \mathrm{VCL}$ and greater for $N \mathrm{VP}$, making the latter system an even poorer donor than NVA.

As shown in Figure 5, the OMRP equilibrium must take into account the possible coordination of ligands to the $\mathrm{Co}^{\mathrm{II}}$ and $\mathrm{Co}^{\mathrm{III}}$ species. In the case of the $\mathrm{Co}(\mathrm{acac})_{2}$-mediated VAc polymerization, the monomer itself is a poor ligand and calculations have indicated that its coordination to the 5-coordinate $\mathrm{Co}^{\mathrm{III}}$ complex is less favored than the chain end chelation, while coordination to $\mathrm{Co}(\mathrm{acac})_{2}$ is largely unfavored. Better ligands such as DMF (in Figure 5), DMSO, pyridine or water, on the other hand, can indeed coordinate to both species. The vinyl amide monomers examined here are better donors than the ester function of VAc thanks to the greater contribution of the polar mesomeric $\mathrm{O}^{-} \mathrm{C}(\mathrm{R})=\mathrm{N}^{+}$form, but their donor ability relative to ligands such as DMF is not clear. In order to evaluate the contribution of monomer coordination, additional calculations were carried out on the 6-coordinate mono-adduct of the $\mathrm{Co}^{\mathrm{III}}$ system and bis-adduct of the $\mathrm{Co}^{\mathrm{II}}$ system. The 5-coordinate $\mathrm{Co}(\mathrm{acac})_{2}$ (monomer) complex, being less relevant to the thermodynamic balance, was not calculated. The enthalpy balance of the two equilibria (equations 1 and $2 ; \mathrm{M}=$ monomer; $\mathrm{MH}=$ radical associated to the monomer, model of the polymer chain) are shown in Table 3, and graphically in Figures S6a-e in the Supporting Information.

$$
\begin{aligned}
& \kappa^{1}: C-\mathrm{Co}(\mathrm{acac})_{2}(\mathrm{MH})+\mathrm{M} \rightarrow \mathrm{Co}(\mathrm{acac})_{2}(\mathrm{MH})(\mathrm{M}) \\
& \mathrm{Co}(\mathrm{acac})_{2}+2 \mathrm{M} \rightarrow \mathrm{Co}(\mathrm{acac})_{2}(\mathrm{M})_{2}
\end{aligned}
$$

Table 3. Calculated enthalpy changes (in $\mathrm{kcal} / \mathrm{mol}$ ) of the monomer coordination to the $\mathrm{Co}^{\mathrm{III}}$ and $\mathrm{Co}^{\mathrm{II}}$ species.

\begin{tabular}{lcc}
\hline Monomer & Eq. 1 & Eq. 2 \\
\hline$N$ VP & +1.1 & -0.4 \\
$N V C L$ & +7.1 & +2.1 \\
$N$ VMA & 0.0 & +0.2 \\
$N$ VA & -1.2 & -1.8 \\
$N$ VF & -2.6 & -2.2 \\
\hline
\end{tabular}

The results show that the vinyl amide monomers, although indeed better ligands than VAc as expected, bind less strongly than DMF to both $\mathrm{Co}^{\mathrm{III}}$ and $\mathrm{Co}^{\mathrm{II}}$ (Figure 5). The primary amides $N \mathrm{VA}$ and $N \mathrm{VF}$ afford mildly exothermic interactions in both oxidation states, whereas the secondary amides afford thermoneutral (NVMA) or endothermic (NVP, NVCL) interactions. In this respect, it is interesting to note that, whereas the literature contains numerous $\mathrm{X}$ ray structures of bis-L adducts of $\operatorname{di}(\beta$-diketonato)cobalt(II), the only members of this family containing a carbonyl-based ligand (ketone, ester, amide, ...) are those where L $=$ DMF.$^{[53,59,60]}$ The observed trend of binding enthalpies can once again be attributed to the steric pressure exerted by the alkyl substituents. Given these results, it seems that the contribution of monomer coordination to the dormant species and to the $\mathrm{Co}(\mathrm{acac})_{2}$ trapping complex is negligible or very small. In fact, coordination to the alkylcobalt(III) system is less favorable, for all five monomers, than chelation by the carbonyl functionality. Therefore, the best parameter to describe the radical controlling equilibrium is the enthalpy difference between the chelated $\kappa^{2}: C, O-C o(a c a c)_{2}(\mathrm{MH})$ complex and the separate $\mathrm{Co}(\mathrm{acac})_{2}$ and $\mathrm{MH}^{*}$ radical species (i.e. the $\kappa^{2}: C, O \mathrm{BDE}$ in the last column of Table 3), except perhaps for the $N \mathrm{VA}$ and especially $N \mathrm{VF}$ systems where the $\mathrm{Co}^{\mathrm{II}}$ stabilization may result in an accelerating effect. Remember that these calculated enthalpic parameters are not a direct 
measure of the ligand association/dissociation equilibria since the entropic component is not included. However, since the -TS contribution is small and not greatly different for the various systems, the trend of the calculated $\Delta \mathrm{H}$ should be representative of the real trend of $\Delta \mathrm{G}$.

The enthalpy difference between dormant and trapping complexes is therefore ranked in the following decreasing order (values in kcal/mol): NVMA (16.5) > NVCL (14.7) > NVA (12.3) > $N$ VP (11.6) $>N V F$ (10.8). Note that this order is in quite good agreement with the relative order of polymerization rate, since $N$ VMA polymerizes more slowly than NVCL (see Figure 1) and the polymerization of the other three monomers is much faster. The only apparent disagreement between the bond strength order and the rate of polymerization appears to be the relative positioning of $N \mathrm{VP}$, the polymerization of which, although quite fast, is not as fast as those of $N \mathrm{VA}$ and NVF. It seems that the enthalpy differences analyzed above are overevaluated for the two latter monomer systems. Possible differences in the propagation rate constant may be invoked to explain the discrepancy, but according to the literature (see above), the $k_{\mathrm{p}}$ values for $N \mathrm{VP}$ and $N \mathrm{VF}$ are not too different under similar conditions. We therefore wondered whether the discrepancy could be explained by the intervention of hydrogen bonding.

The possibility for the free monomer to establish hydrogen bonds can further affect the equilibria of Scheme 2 for the NVA and $N$ VF systems. Indeed, as shown in Scheme 5, both the free radical and the cobalt $\kappa^{1}: C$-bonded radical have three possible ways to establish a hydrogen bond with free monomer: $\mathrm{N}$ $\mathrm{H}$ (radical) $\cdots \mathrm{O}=\mathrm{C}($ monomer $), \mathrm{N}-\mathrm{H}($ monomer $) \cdots \mathrm{O}=\mathrm{C}$ (radical), and a cyclic structure with both types of interactions. The latter is in principle energetically preferred although it forces a less favorable $s$-E conformation around the $\mathrm{N}-\mathrm{C}(\mathrm{O})$ bond in both radical and monomer. On the other hand, the chelated hexacoordinated complex, with the carbonyl function tied up in cobalt coordination and therefore unavailable for hydrogen bonding, can only form the $\mathrm{N}-\mathrm{H}$ (radical) $\cdots \mathrm{O}=\mathrm{C}$ (monomer) interaction and therefore suffers from a reduced stabilization. This argument predicts that hydrogen bonding will stabilize the free radical $+\mathrm{Co}(\mathrm{acac})_{2}$ to a greater extent than the chelated dormant state, with a net accelerating effect for the polymerization.

The calculations qualitatively confirm this view. The stabilization of the dormant species on the enthalpy scale is worth only $2.0 \mathrm{kcal} / \mathrm{mol}$ for the $N \mathrm{VA}$ system and $3.2 \mathrm{kcal} / \mathrm{mol}$ for the $N \mathrm{VF}$ system, whereas the free radical is indeed most stabilized by the double interaction, as shown in Scheme 5, by $13.1 \mathrm{kcal} / \mathrm{mol}$ for the $N$ VA system and by $15.1 \mathrm{kcal} / \mathrm{mol}$ for the $N \mathrm{VF}$ system. Figures showing the complete energy diagrams for the two systems and views of the optimized geometries are shown in the Supporting Information (Figure S7). This substantial difference in relative stabilization largely affects the position of the equilibrium between latent and free radical and rationalizes the very large difference in polymerization rate between the $N \mathrm{VA}$ and $N \mathrm{VF}$ systems on one side and the NVP on the other side.

In light of the above computational results, it is also possible to rationalize the good level of control achieved for the statistical copolymerization of $N \mathrm{VA}$ and $N \mathrm{MVA}$, with a polymerization rate not much greater than that of the NMVA homopolymerization and much smaller than that of the NVA homopolymerization. According to our computational model, the $\mathrm{Co}(\mathrm{acac})_{2}$ controlling agent is able to efficiently moderate the concentration of the NMVA related radicals and much less that of the NVA related radicals. Therefore, the longer life dormant chain in the copolymerization will contain a Co(acac)2-bonded NMVA monomer unit. Given the 50:50 ratio in the comonomer feed and a nearly equivalent ratio found in the polymer, the reactivity ratios are probably quite close to 1 and the polymerization rate should ideally be multiplied by a factor of two. On the other hand, even though the presence of the NVA comonomer can establish H-bonds with both dormant and active chains, the extent of these interactions should be nearly identical when the chain is terminated by an NMVA unit and the energetic scheme for the activation/deactivation equilibrium should remain essentially unaltered.

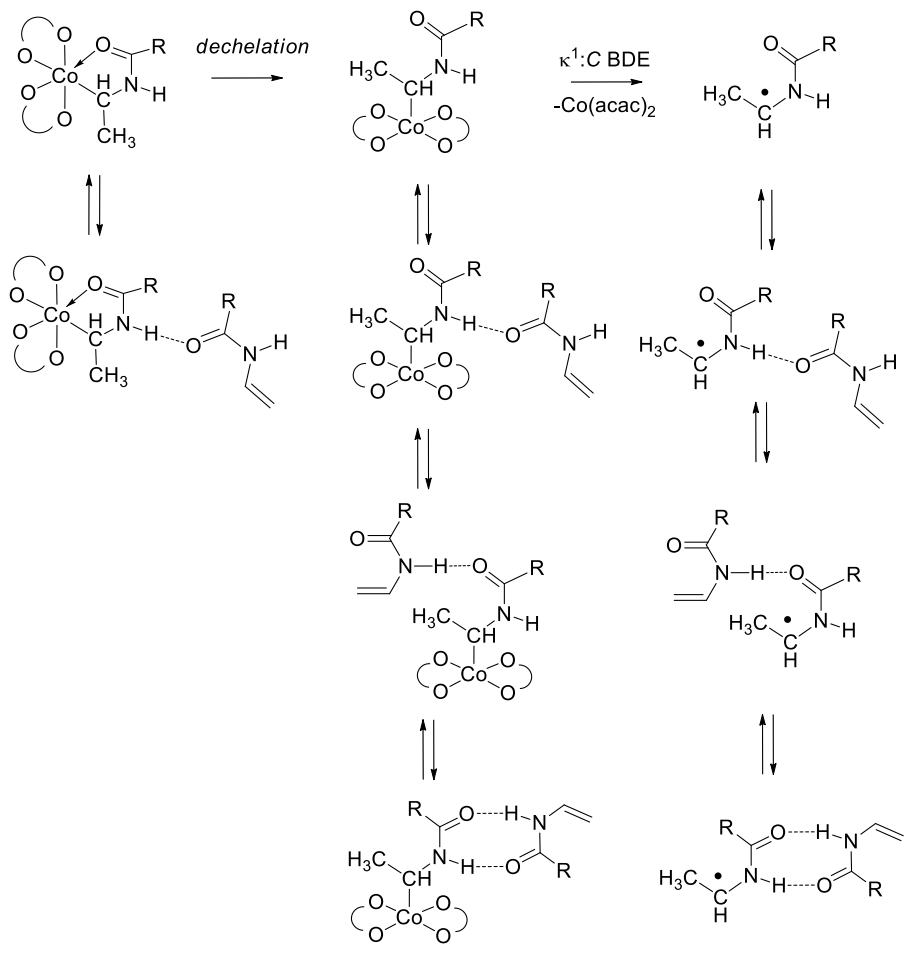

Scheme 5. Effect of hydrogen bonding on the dechelation and homolytic bond cleavage processes for the formant species in $\mathrm{Co}(\mathrm{acac})_{2}$-mediated polymerization of $N \mathrm{VA}(\mathrm{R}=$ $\left.\mathrm{CH}_{3}\right)$ and $N \mathrm{VF}(\mathrm{R}=\mathrm{H})$; the acetylacetonate ligands are simplified for clarity.

\section{Conclusion}

The radical polymerization of various $N$-vinyl amides, including cyclic and acyclic monomers, was carried out in bulk at $40^{\circ} \mathrm{C}$ using an alkyl-Co(acac) 2 derivative as initiator. Very well-defined $\mathrm{PNVCl}$ and PNMVA were produced, confirming that CMRP is a technique of choice for unconjugated monomers. We also found that the polymerization rate of three monomers with very similar electronic properties decreases in the order $N \mathrm{VP}>N \mathrm{VCL}>N \mathrm{MVA}$. A DFT study revealed that intramolecular chelation of the cobalt by the amide moiety in the last monomer unit of the dormant species, generating a 5-member ring, accounts for the observed differences in the kinetics and the control. Such coordination contributes to the stabilization of the dormant species and slows down the polymerization, making the polymerization control more efficient. The absence of ring tension in the NMVA explains the preponderance of the chelation effect in the polymer-cobalt(III) derivative in contrast to $N \mathrm{VP}$. The $N \mathrm{VCL}$ is intermediate because its lactam ring is larger and less strained than NVP. The competitive 
coordination of the cobalt(III) dormant species and cobalt(II) trapping complex by the free monomer was also considered but evaluated negligible or very small. This intramolecular chelation phenomenon is however insufficient to describe the behavior of secondary $N$-vinyl amides, i.e. $N \mathrm{VF}$ and $N \mathrm{VA}$. The polymerization of these monomers is extremely fast and suffers from poor or no control. In these polymerizations, the different ability of the free monomer, through the formation of $\mathrm{N}-\mathrm{H} \cdots \mathrm{O}=\mathrm{C}$ hydrogen bonds, to stabilize the dormant chains (only as proton donor) and the growing radical chains (both as proton donor and as proton acceptor) excessively shifts the equilibrium towards the propagating radical form. Nevertheless, these monomers are not precluded from use in the CMRP since addition of NMVA as a comonomer leads to controlled copolymerization. This detailed kinetic and mechanistic study and the essential role played by this unique intramolecular chelation phenomenom is a crucial step in the development of an efficient synthetic platform for a wide range well-defined poly $(N$ vinyl amide)s (co)polymers of high interest.

\section{Experimental Section}

Materials. Vinyl acetate (>99\%, Aldrich), $N$-methyl-N-vinyl acetamide (Aldrich, $98 \%$ ), $N$-vinyl pyrrolidone (Aldrich, >99\%), $N$-methyl-N-vinyl formamide (Aldrich, 98\%), dimethylformamide (\%), $N$-methyl-formamide (Aldrich, 99\%) were dried over calcium hydride, degassed by several freeze-pump-thaw cycles before being distilled under reduced pressure and stored under argon. $\mathrm{N}$-vinyl caprolactam (Aldrich, 98\%), $\mathrm{N}$ vinyl acetamide (TCI, >98\%), 2,2,6,6-tetramethylpiperidine 1-oxyl (TEMPO, 98\%, Aldrich), cobalt(II) acetylacetonate ( $>98 \%$, Acros), were used as received. The alkyl cobalt(III) adduct initiator $\left(\left[\mathrm{Co}(\mathrm{acac})_{2}\left(\left(\left(\mathrm{OCOCH}_{3}\right) \mathrm{CH}_{2}\right)_{4} \mathrm{R}_{0}\right)\right] ; \mathrm{R}_{0}\right.$ being the primary radical generated by 2,2'-azo-bis(4-methoxy-2,4-dimethyl valeronitrile) (V-70, Wako) was prepared as described previously. ${ }^{[21]}$ The cobalt content of the alkyl cobalt solution in dichloromethane solution was evaluated $([\mathrm{Co}]=0.143 \mathrm{M})$.

Characterization. The molecular parameters of PNVP, PNVCL, PNMVA, PNVA-coPNMVA, were determined by size exclusion chromatography (SEC) in dimethylformamide (DMF) containing some $\mathrm{LiBr}(0.025 \mathrm{M})$ at $55^{\circ} \mathrm{C}$ (flow rate: $1 \mathrm{~mL}$ min-1), with a Waters 600 liquid chromatograph equipped with a 410 refractive index detector and styragel HR columns (HR1, 100-5000; HR3, 500-30000; HR4, 5000500000; HR5, 2000-4000000) using a polystyrene calibration. Absolute molecula weight of PNVP, PNVCL, PNMVA, samples were determined using a Multi-Angle Laser Light Scattering (MALLS) detector. The specific refractive index increment $(\mathrm{dn} / \mathrm{dc})$ was determined for each polymer using a Wyatt Optilab rEXrefractive index detector $(\lambda=658 \mathrm{~nm}$ ). Data were processed with the Astra V software (Wyatt Technology). Molecular parameters of PVAc were determined by Size Exclusion Chromatography (SEC) relative to polystyrene standards in tetrahydrofuran (THF, flow rate: $1 \mathrm{~mL} \mathrm{~min}^{-1}$ ) at $40{ }^{\circ} \mathrm{C}$ with a Waters 600 liquid chromatograph equipped with a 410 refractive index detector and styragel HR columns (four HP PL gel $5 \mu \mathrm{m}$ columns: $10^{5}$, $10^{4}, 10^{3}$, and $10^{2} \AA$ ). According to a previous report, ${ }^{[16]}$ the molar mass of a PVAc sample determined with a PS calibration is close to the absolute molecular weight unde these elution conditions. Molecular parameters of the PVF was determined by Size Exclusion Chromatography in water $(\mathrm{pH}=3.9$, buffer: acetic acid $=0.3 \mathrm{M}$, sodium acetate $=0.2 \mathrm{M}$, sodium azide $0.02 \mathrm{wt} \%$ ) (flow rate $0.8 \mathrm{~mL} \mathrm{~min}{ }^{-1}$ ) at $30^{\circ} \mathrm{C}$, with a Waters chromatograph equipped with a refractive index detector and four columns (Ultrahydrogel 120, 250, 500, 1000). ${ }^{1} \mathrm{H}$ NMR spectra of the polymers and reaction mixtures were recorded at $353 \mathrm{~K}$ with a $400 \mathrm{MHz}$ Bruker spectrometer.

Cobalt-mediated radical polymerization of NMVA. A solution of alkyl-cobalt(III) initiator $\left(\left[\mathrm{Co}(\mathrm{acac})_{2}\left(\left(\left(\mathrm{OCOCH}_{3}\right) \mathrm{CH}_{2}\right)_{<4} \mathrm{R}_{0}\right)\right]\right.$ in $\left.\mathrm{CH}_{2} \mathrm{Cl}_{2}\right)$ was introduced under argon in a Schlenk tube $(1.0 \mathrm{~mL}$ of a $0.143 \mathrm{M}$ stock solution, $0.143 \mathrm{mmol})$ and evaporated to dryness under reduced pressure at room temperature. The residue was dissolved in $N$ MVA $(5.60 \mathrm{~mL}, 54.2 \mathrm{mmol})([\mathrm{NMVA}] /[\mathrm{Co}]=380)$ at room temperature. The Schlenk was then immersed and stirred in an oil bath at $40^{\circ} \mathrm{C}$. Aliquots were regularly withdrawn to evaluate the monomer conversion and the molecular parameters. The aliquots were treated with TEMPO, which replaces $\mathrm{Co}(\mathrm{acac})_{2}$ as chain end, ${ }^{[61]}$ before dilution in DMF in order to measure $\mathrm{Mn}_{\mathrm{n}}$ and $\mathrm{M}_{\mathrm{w}} / \mathrm{M}_{\mathrm{n}}$ of the PNMVA by SEC-MALLS using DMF as eluent $(\mathrm{dn} / \mathrm{dc}$ of PNMVA $=0.071 \mathrm{~mL} / \mathrm{g})$. The monomer conversion was determined by weighing the collected polymer after removal of the unconverted monomer in vacuo at $60^{\circ} \mathrm{C}$.

The same general procedure was followed for the CMRP of VAc, $N$ VP, $N$ VF. The VAc conversion was evaluated by gravimetry whereas $N \mathrm{VP}$ and $N \mathrm{VF}$ consumption were determined by ${ }^{1} \mathrm{H}$ NMR analyses in $\mathrm{CDCl}_{3}$ and $\mathrm{D}_{2} \mathrm{O}$, respectively. The molecular parameters of PVAc, PNVP and PNVF, were measured by SEC in THF with a PS calibration, by SEC-MALLS in DMF $(\mathrm{dn} / \mathrm{dc}=0.064 \mathrm{~mL} / \mathrm{g})$ and by SEC in water using PEO as calibration, respectively.

Cobalt-mediated radical polymerization of $N \mathrm{VCL}$. The experiment was realized in a system composed of two flasks connected via a male-female junction. The NVCL (7.55 $\mathrm{g}, 54.2 \mathrm{mmol}$ ) was introduced as a solid under argon in one flask. A solution of alkylcobalt(III) initiator $\left(\left[\mathrm{Co}(\mathrm{acac})_{2}\left(\left(\left(\mathrm{OCOCH}_{3}\right) \mathrm{CH}_{2}\right)_{4} \mathrm{R}_{0}\right)\right]\right.$ in $\left.\mathrm{CH}_{2} \mathrm{Cl}_{2}\right)$ was introduced under argon in the second flask $(1.0 \mathrm{~mL}$ of a $0.143 \mathrm{M}$ stock solution, $0.143 \mathrm{mmol})$ and evaporated to dryness under reduced pressure at room temperature, and the reactor was then refilled with argon. The $N \mathrm{VCL}\left(\mathrm{mp}=35-38^{\circ} \mathrm{C}\right)$ was melted at $40^{\circ} \mathrm{C}$ before being transferred onto the alkyl-cobalt(III) initiator. The polymerization mixture was stirred at $40^{\circ} \mathrm{C}$ and samples were regularly withdrawn from the medium. The monomer conversion was evaluated by ${ }^{1} \mathrm{H}$ NMR analysis in $\mathrm{CDCl}_{3}$. The PNVCL samples were precipitated in $\mathrm{Et}_{2} \mathrm{O}$ before determining the $\mathrm{M}_{\mathrm{n}}$ and $\mathrm{M}_{\mathrm{w}} / \mathrm{M}_{\mathrm{n}}$ by SEC-MALLS in DMF $(\mathrm{dn} / \mathrm{dc}=0.0825 \mathrm{~mL} / \mathrm{g})$

The same procedure was used for the CMRP of $N \mathrm{VA}\left(\mathrm{mp} 55^{\circ} \mathrm{C}\right.$ ) at $60^{\circ} \mathrm{C}$. The $\mathrm{M}_{\mathrm{n}}$ and $\mathrm{M}_{\mathrm{w}} / \mathrm{M}_{\mathrm{n}}$ of the PNVA collected at the end of the polymerization were obtained by SECMALLS in DMF $(\mathrm{dn} / \mathrm{dc}=0.060 \mathrm{~mL} / \mathrm{g})$.

Cobalt-mediated radical copolymerization of $N \mathrm{VA}$ and $N \mathrm{MVA}$ in bulk. A solution of alkyl-cobalt(III) initiator $\left(\left[\mathrm{Co}(\mathrm{acac})_{2}\left(\left(\left(\mathrm{OCOCH}_{3}\right) \mathrm{CH}_{2}\right)_{<4} \mathrm{R}_{0}\right)\right]\right.$ in $\left.\mathrm{CH}_{2} \mathrm{Cl}_{2}\right)$ was introduced under argon in a Schlenk tube $(1.0 \mathrm{~mL}$ of a $0.143 \mathrm{M}$ stock solution, 0.143 $\mathrm{mmol}$ ) and evaporated to dryness under reduced pressure at room temperature. After refilling the Schlenk tube with argon, the residue was dissolved in NMVA $(1.40 \mathrm{~mL}$, $13.5 \mathrm{mmol})$ at room temperature and transferred under argon to a second flask containing the NVA $(1.15 \mathrm{~g}, 13.5 \mathrm{mmol})$. After complete dissolution of $N \mathrm{VA}$ in the $N$ MVA solution, the mixture was immersed and stirred in an oil bath at $40^{\circ} \mathrm{C}$. Aliquots were regularly withdrawn from the polymerization medium. The aliquots were treated with TEMPO before dilution in DMF in order to measure $M_{n}$ and $M_{w} / M_{n}$ of the copolymer by SEC using DMF as eluent and PS as a calibration (Figure 4).

The composition of a PNVA-co-PNMVA sample, prepared under the same conditions (reaction time $=80$ minutes, monomer conversion $=36 \%$ ) and purified by precipitation in diethyl ether before drying under vacuum, was determined by ${ }^{1} \mathrm{H}$ NMR analysis in $\mathrm{D}_{2} \mathrm{O}(N \mathrm{VA} / N \mathrm{MVA}$ molar ratio in the copolymer $=55 / 45$, Figure $\mathrm{S} 4)$.

Computational details. For consistency, the computational work was carried out at the same theoretical level as the previous contribution on the $\mathrm{Co}(\mathrm{acac})_{2}$-mediated polymerization of VAc in the presence of various Lewis bases, ${ }^{[21,28]}$ using the Gaussian03 suite of programs. ${ }^{[62]}$ The geometry optimizations were performed without any symmetry constraint using the B3PW91* functional, a modified version of the B3PW91 functional, in which the $c_{3}$ coefficient in Becke's original three-parameter fit to thermochemical data was changed to 0.15 . The $6-31 \mathrm{G} * *$ basis functions were used for all light atoms $(\mathrm{H}, \mathrm{C}, \mathrm{N}, \mathrm{O})$ where the Co atom was treated with the LANL2DZ function augmented by an $\mathrm{f}$ polarization function $(\alpha=0.8)$. The unrestricted formulation was used for open-shell molecules, yielding only minor spin contamination $\left(\left\langle S^{2}\right\rangle\right.$ at convergence was very close to the expected value of 0.75 for the radical species and 3.75 for the spin quartet species). All final geometries were characterized as local minima by verifying that all second derivatives of the energy were positive. Thermochemical corrections were obtained at $298.15 \mathrm{~K}$ on the basis of frequency calculations, using the standard approximations (ideal gas, rigid rotor and harmonic oscillator).

\section{Acknowledgements}

The authors from Liège are grateful to the Fonds National de la Recherche Scientifique (FRS-FNRS) and to the Belgian Science Policy for financial support in the frame of the Interuniversity Attraction Poles Programme (PAI VI/27)-Functional Supramolecular Systems. A.D. and C.D. are associate researcher and senior researcher at the FNRS, respectively. RP thanks the Centre National de la Recherche Scientifique (CNRS), the Institut Universitaire de France (IUF) and the Agence National de la Recherche (project OMRP, grant ANR 2010 BLANC 7101) for financial support of this work. In addition, this work was granted access to the HPC resources of CINES under the allocation 2010-086343 made by GENCI (Grand Equipement National de Calcul Intensif) and to the resources of the CICT (Centre Interuniversitaire de Calcul de Toulouse, project CALMIP).The authors also thank G. Cartigny for skillful assistance.

[1] C. W. Bielawski and R. H. Grubbs, Prog. Polym. Sci. 2007, 32, 1-29.

[2] G. J. Domski, J. M. Rose, G. W. Coates, A. D. Bolig and M. Brookhart, Prog. Polym. Sci. 2007, 32, 30-92.

[3] E. Y. X. Chen, Chem. Rev. 2009, 109, 5157-5214.

[4] A. Nakamura, S. Ito and K. Nozaki, Chem. Rev. 2009, 109, 5215-5244.

[5] F. Di Lena and K. Matyjaszewski, Prog. Polym. Sci. 2010, 35, 959-1021.

[6] M. Ouchi, T. Terashima and M. Sawamoto, Chem. Rev. 2009, 109, 4963-5050.

[7] W. Tang, Y. Kwak, W. Braunecker, N. V. Tsarevsky, M. L. Coote and K Matyjaszewski, J. Am. Chem. Soc. 2008, 130, 10702-10713.

[8] H. Tang, N. Arulsamy, M. Radosz, Y. Shen, N. V. Tsarevsky, W. A Braunecker, W. Tang and K. Matyjaszewski, J. Am. Chem. Soc. 2006, 128, 16277-16285. 
[9] M. Kamigaito, Y. Watanabe, T. Ando and M. Sawamoto, J. Am. Chem. Soc 2002, 124, 9994-9995.

[10] R. Poli, Angew. Chem. Int. Ed. 2006, 45, 5058-5070.

[11] M. Hurtgen, C. Detrembleur, C. Jerome and A. Debuigne, Polym. Rev. 2011, 51, 188-213.

[12] L. E. N. Allan, M. R. Perry and M. P. Shaver, Prog. Polym. Sci. 2012, 37, 127156.

[13] A. Debuigne, R. Poli, C. Jerome, R. Jerome and C. Detrembleur, Prog. Polym. Sci. 2009, 34, 211-239.

[14] A. Debuigne, J.-R. Caille, C. Detrembleur and R. Jerome, Angew. Chem., Int Ed. 2005, 44, 3439-3442.

[15] Y. Champouret, U. Baisch, R. Poli, L. Tang, J. L. Conway and K. M. Smith, Angew. Chem. Int. Ed. 2008, 47, 6069-6072.

[16] A. Debuigne, J.-R. Caille and R. Jerome, Angew. Chem., Int. Ed. 2005, 44 1101-1104.

[17] B. B. Wayland, G. Poszmik, S. L. Mukerjee and M. Fryd, J. Am. Chem. Soc 1994, 116, 7943-7944

[18] C.-H. Peng, M. Fryd and B. B. Wayland, Macromolecules 2007, 40, 6814-6819.

[19] C.-H. Peng, J. Scricco, S. Li, M. Fryd and B. B. Wayland, Macromolecules 2008, 41, 2368-2373.

[20] M. R. Buchmeiser, M. G. Marino, Macromol. Mater. Eng. 2012, DOI 10.1002/mame.201100358

[21] A. Debuigne, Y. Champouret, R. Jerome, R. Poli and C. Detrembleur, Chem Eur. J. 2008, 14, 4046-4059.

[22] H. Kaneyoshi and K. Matyjaszewski, Macromolecules 2006, 39, 2757-2763.

[23] A. Debuigne, N. Willet, R. Jerome and C. Detrembleur, Macromolecules 2007, 40, 7111-7118

[24] A. Debuigne, R. Poli, W. J. De, P. Laurent, P. Gerbaux, J.-P. Wathelet, C. Jerome and C. Detrembleur, Macromolecules 2010, 43, 2801-2813.

[25] A. Debuigne, M. Schoumacher, N. Willet, R. Riva, X. Zhu, S. Ruetten, C. Jerome and C. Detrembleur, Chem. Commun. 2011, 47, 12703-12705.

[26] C. Detrembleur, A. Debuigne, M. Hurtgen, C. Jerome, J. Pinaud, M. Fevre, P. Coupillaud, J. Vignolle and D. Taton, Macromolecules 2011, 44, 6397-6404.

[27] S. Maria, H. Kaneyoshi, K. Matyjaszewski and R. Poli, Chem. Eur. J. 2007, 13, 2480-2492.

[28] A. Debuigne, R. Poli, R. Jerome, C. Jerome and C. Detrembleur, ACS Symp. Ser. 2009, 1024, 131-148.

[29] K. Santhosh, Y. Gnanou, Y. Champouret, J.-C. Daran and R. Poli, Chem. Eur. J. 2009, 15, 4874-4885.

[30] A. Debuigne, J. Warnant, R. Jerome, I. Voets, A. de Keizer, M. A. Cohen Stuart and C. Detrembleur, Macromolecules 2008, 41, 2353-2360.

[31] M. Hurtgen, J. Liu, A. Debuigne, C. Jerome and C. Detrembleur, J. Polym. Sci., Part A: Polym. Chem. 2012, 50, 400-408.

[32] T. L.U. Nguyen, K. Eagles, T. P. Davis, C. Barner-Kowollik and M. H. Stenzel, J. Polym. Sci., Part A: Polym. Chem. 2006, 44, 4372-4383.

[33] G. Pound, J. B. McLeary, J. M. McKenzie, R. F. M. Lange and B. Klumperman, Macromolecules 2006, 39, 7796-7797.

[34] D. Wan, K. Satoh, M. Kamigaito and Y. Okamoto, Macromolecules 2005, 38 , 10397-10405

[35] A. K. Mishra, V. K. Patel, N. K. Vishwakarma, C. S. Biswas, M. Raula, A. Misra, T. K. Mandal and B. Ray, Macromolecules 2011, 44, 2465-2473

[36] D. Wan, Q. Zhou, H. Pu and G. Yang, J. Polym. Sci., Part A: Polym. Chem. 2008, 46, 3756-3765.

[37] M. Beija, J.-D. Marty and M. Destarac, Chem. Commun. 2011, 47, 2826-2828.

[38] S.-I. Yusa, S. Yamago, M. Sugahara, S. Morikawa, T. Yamamoto and Y. Morishima, Macromolecules 2007, 40, 5907-5915.

[39] S. Yamago, B. Ray, K. Iida, J. Yoshida, T. Tada, K. Yoshizawa, Y. Kwak, A. Goto and T. Fukuda, J. Am. Chem. Soc. 2004, 126, 13908-13909.

[40] B. Ray, M. Kotani and S. Yamago, Macromolecules 2006, 39, 5259-5265.

[41] S. Yamago, T. Yamada, M. Togai, Y. Ukai, E. Kayahara and N. Pan, Chem. Eur. J. 2009, 15, 1018-1029.

[42] S. Yamago, E. Kayahara, M. Kotani, B. Ray, Y. Kwak, A. Goto and T. Fukuda Angew. Chem., Int. Ed. 2007, 46, 1304-1306

[43] A. Imaz and J. Forcada, J. Polym. Sci., Part A: Polym. Chem. 2010, 48, 11731181
[44] F. Meeussen, E. Nies, H. Berghmans, S. Verbrugghe, E. Goethals and P. F. Du, Polymer 2000, 41, 8597-8602

[45] T. Mori, Y. Fakuda, H. Okamura, K. Minagawa, S. Masuda and M. Tanaka, J. Polym. Sci., Part A: Polym. Chem. 2004, 42, 2651-2658

[46] Y. E. Kirsh, Water Soluble Poly-N-Vinylamides : Synthesis and Physicochemical Properties, Wiley, New York, 1998.

[47] H. Vihola, A. Laukkanen, L. Valtola, H. Tenhu and J. Hirvonen, Biomaterial 2005, 26, 3055-3064

[48] Y. Takemoto, H. Ajiro, T.-a. Asoh and M. Akashi, Chem. Mater. 2010, 22, 2923-2929.

[49] S. Sakuma, H. Higashino, H. Oshitani, Y. Masaoka, M. Kataoka, S. Yamashita, K.-I. Hiwatari, H. Tachikawa, R. Kimura, K. Nakamura, H. Kumagai, J. C. Gore and W. Pham, Eur. J. Pharm. Biopharm. 2011, 79, 537-543

[50] S. Sakuma, T. Yano, Y. Masaoka, M. Kataoka, K.-I. Hiwatari, H. Tachikawa, Y. Shoji, R. Kimura, H. Ma, Z. Yang, L. Tang, R. M. Hoffman and S. Yamashita, J. Controlled Release 2009, 134, 2-10.

[51] H. Ajiro, Y. Takemoto, M. Akashi, P. C. Chua and M. A. Kelland, Energy Fuels 2010, 24, 6400-6410.

[52] R. O'Reilly, N. S. Ieong, P. C. Chua and M. A. Kelland, Chem. Eng. Sci. 2011, 66, 6555-6560.

[53] A. Debuigne, C. Michaux, C. Jerome, R. Jerome, R. Poli and C. Detrembleur, Chem. Eur. J. 2008, 14, 7623-7637

[54] M. Hurtgen, A. Debuigne, C. Jerome and C. Detrembleur, Macromolecules 2010, 43, 886-894

[55] A. Debuigne, R. Poli, W. J. De, P. Laurent, P. Gerbaux, P. Dubois, J.-P Wathelet, C. Jerome and C. Detrembleur, Chem. Eur. J. 2010, 16, 1799-1811

[56] K. M. Gibov and G. P. Gladyshev, Izv. Akad. Nauk Kaz. SSR, Ser. Khim. 1967, $17,53-56$

[57] J. Brandrup, E. H. Immergut and E. A. Grulke, Polymer Handbook 4th ed, John Wiley \& Sons, Inc., Hoboke, NJ, 1999.

[58] M. Stach, I. Lacik, P. Kasak, D. Chorvat, Jr., A. J. Saunders, S. Santanakrishnan and R. A. Hutchinson, Macromol. Chem. Phys. 2010, 211, 580-593

[59] J. Casabo, J. Marquet, M. Moreno-Manas, M. Prior, F. Teixidor, F. Florencio, S Martinez-Carrera and S. Garcia-Blanco, Polyhedron 1987, 6, 1235-1238.

[60] G. Aromi, C. Boldron, P. Gamez, O. Roubeau, H. Kooijman, A. L. Spek, H. Stoeckli-Evans, J. Ribas and J. Reedijk, Dalton Trans. 2004, 3586-3592

[61] A. Debuigne, J.-R. Caille and R. Jerome, Macromolecules 2005, 38, 5452-5458.

[62] M. J. Frisch, G. W. Trucks, H. B. Schlegel, G. E. Scuseria, M. A. Robb, J. R. Cheeseman, J. Montgomery, J. A., T. Vreven, K. N. Kudin, J. C. Burant, J. M. Millam, S. S. Iyengar, J. Tomasi, V. Barone, B. Mennucci, M. Cossi, G. Scalmani, N. Rega, G. A. Petersson, H. Nakatsuji, M. Hada, M. Ehara, K. Toyota, R. Fukuda, J. Hasegawa, M. Ishida, T. Nakajima, Y. Honda, O. Kitao, H. Nakai, M. Klene, X. Li, J. E. Knox, H. P. Hratchian, J. B. Cross, C. Adamo, J. Jaramillo, R. Gomperts, R. E. Stratmann, O. Yazyev, A. J. Austin, R. Cammi, C. Pomelli, J. W. Ochterski, P. Y. Ayala, K. Morokuma, G. A. Voth, P. Salvador, J. J. Dannenberg, V. G. Zakrzewski, S. Dapprich, A. D. Daniels, M. C. Strain, O. Farkas, D. K. Malick, A. D. Rabuck, K. Raghavachari, J. B. Foresman, J. V. Ortiz, Q. Cui, A. G. Baboul, S. Clifford, J. Cioslowski, B. B. Stefanov, G. Liu, A. Liashenko, P. Piskorz, I. Komaromi, R. L. Martin, D. J. Fox, T. Keith, M. A. Al-Laham, C. Y. Peng, A. Nanayakkara, M. Challacombe, P. M. W. Gill, B. Johnson, W. Chen, M. W. Wong, C. Gonzalez, J. A. Pople, Gaussian 03, Revision C.02, Gaussian, Inc., Wallingford CT 2004

Received: ((will be filled in by the editorial staff)) Revised: ((will be filled in by the editorial staff)) Published online: ((will be filled in by the editorial staff)) 


\section{Entry for the Table of Contents}

Two bonds are better than one!

Antoine Debuigne, *Aurélie N. Morin, Anthony Kermagoret, Yasmine Piette, Christophe Detrembleur, Christine Jérôme and Rinaldo Poli* ... Page - Page

Key Role of Intramolecular Metal Chelation and Hydrogen

Bonding in the Cobalt-Mediated Radical Polymerization of $N$ Vinyl amides.

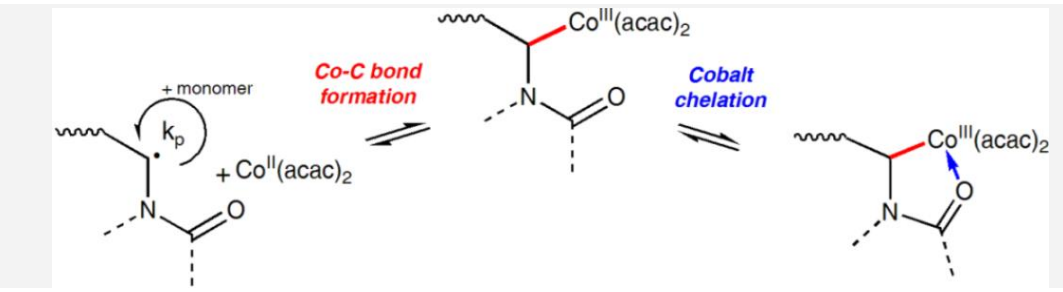

In addition to the reversible cobalt-carbon bond formation, an intramolecular metal chelation phenomenon occurs in cobaltmediated radical polymerization (CMRP) of $N$-vinyl amides. The latter reinforces the metal-polymer bond and allows an optimal control of the polymerizations of $\mathrm{N}$-vinyl caprolactam and $\mathrm{N}$-methyl vinyl acetamide. The detrimental effect of hydrogen bond formation in the CMRP of $N$-vinyl acetamide and $N$-vinyl formamide is also considered. 